\title{
VOC ternary mixture effect on ppb level photocatalytic oxidation: Removal kinetic, reaction intermediates and mineralization
}

\author{
O. Debono ${ }^{\mathrm{a}}$, V. Hequet ${ }^{\mathrm{b}}$, L. Le Coq ${ }^{\mathrm{b}}$, N. Locoge ${ }^{\mathrm{a}}$, F. Thevenet ${ }^{\mathrm{a}, *}$ \\ a IMT Lille Douai, SAGE, Université de Lille, F-59500, Douai, France \\ b IMT Atlantique, GEPEA, UMR CNRS 6144, F-44000 Nantes, France
}

Keywords:

Photocatalytic oxidation

Indoor air

VOC mixture

ppb level

Mineralization

Reaction intermediates

\begin{abstract}
A B S T R A C T
This work addresses photocatalytic oxidation for indoor air purification and more especially the key and realistic issue of VOC mixture treatment. The VOC mixture effect needs to be investigated since indoor air contains several tens of VOCs which may impact photocatalytic oxidation performances. In order to be closer to realistic conditions, concentrations in the ppb range were used and toluene, decane and trichloroethylene (TCE) were treated first as single compounds, then as an equimolar ternary mixture under the same experimental conditions. In a $120 \mathrm{~L}$ batch reactor, VOC removal kinetics, reaction intermediates and $\mathrm{CO}_{2}$ mineralization are addressed using dedicated analytical devices compliant with typical ppb level monitoring. Regarding removal kinetics, the mixture effect affects the three VOCs. Regarding toluene and decane removal kinetic, the mixture effect is evidenced as mostly equivalent to a concentration effect, however TCE kinetic is further impacted. From the reaction intermediate point of view, the accurate monitoring of transiently produced intermediates evidences for the first time cross-reactivity between reaction intermediates originating from different primary VOCs. This phenomenon leading to novel reaction intermediate is mostly induced by chlorinated species produced by TCE degradation but remains moderate. An increase in VOC initial concentration to upper ppb levels emphasized a sequential degradation of primary VOC which may be related to competitive adsorption even on such a low concentration range. Finally, even if the mixture effect delays the removal of the primary VOCs, mineralization is slightly modified and, unlike formerly reported experiments on ppm range, final mineralization rates are equivalent under single or mixture condition at ppb levels. This work highlights the fact that photocatalytic treatment of VOC mixtures cannot be directly extrapolated from single VOC behaviour even at ppb level.
\end{abstract}

\section{Introduction}

According to the World Health Organization, 4.3 million annually premature deaths from diseases, including stroke, ischaemic heart disease, chronic obstructive pulmonary disease (COPD) and lung cancer, could be related to household air pollution exposure [1]. Among various pollutants, Volatile Organic Compounds (VOCs) are pointed out as the major species in that process. Besides ventilation system improvements and the reduction of indoor VOC emission sources from materials, air treatment devices are developed. Several techniques are employed for VOC removal: non-thermal plasma [2], plasma-catalysis [3], adsorption, photo- catalytic oxidation (PCO) [4]. Photocatalytic oxidation is the most widespread technique for indoor air cleaning because it appears as a cheap and flexible solution which possibly mineralizes VOCs, i.e. convert VOCs into $\mathrm{CO}_{2}$ and $\mathrm{H}_{2} \mathrm{O}$. It consists in irradiating with UV light a semiconductor, mostly $\mathrm{TiO}_{2}$. The main drawback of this process is that the oxidation reactions may be incomplete and reaction intermediates can be emitted even in the presence of typical indoor low concentration of VOCs as clearly evidenced by Debono et al. $[5,6]$. In the field of VOC photocatalytic oxidation, most of the investigations are based on single VOC treatment and carried out with ppm levels of pollutants [7,8], whereas indoor air contains several tens of VOCs characterized by ppb level concentrations, i.e. from 0.1 to $100 \mu \mathrm{g} \mathrm{m}^{-3}$ [9]. For instance, more than 44 hydrocarbon VOCs and 6 aldehydes were recently identified and quantified in 7 newly built houses in France [10]. The Total VOC (TVOC) concentrations were up to $570 \mu \mathrm{g} \mathrm{m}^{-3}$, depending on houses and seasons. The con- 
centrations of individual major VOCs varied from 1 to $100 \mu \mathrm{g} \mathrm{m}^{-3}$. However, under specific conditions such as cooking, household cleaning, renovation, etc., concentrations of VOCs can transiently reach concentrations higher than $1500 \mu \mathrm{g} \mathrm{m}^{-3}$ [11].

Thus, in order to explore the performances and limitations of photocatalytic oxidation closer to realistic indoor conditions, it appears necessary to achieve experiments with (i) VOC initial concentrations in the ppb range, and (ii) in the presence of several primary VOCs to assess the impact of VOC mixture on photocatalytic treatment. Formerly published studies dealt with the photocatalytic degradation of toluene and decane as single compounds with typical ppb range initial concentrations $[5,6]$. These studies evidenced that the degradations of toluene and decane follow a pseudo-first-order kinetic. Moreover, the identification and the quantification of reaction intermediates and $\mathrm{CO}_{2}$ also permitted to propose corresponding reaction pathways and carbon mass balances. However, their behaviors have poorly been addressed when treated in mixture at ppb levels whereas they are widespread indoor air VOCs [9].

Former works focused on mixture treatment, but generally involve VOC concentrations higher than $1 \mathrm{ppm}$. From the late 80 's, Ollis et al. worked on the photocatalytic oxidation of organic mixtures, first in water [12], then in air matrixes [13-17]. They demonstrated that trichloroethylene (TCE) and other chlorinated compounds are able to promote the degradation of several VOCs. However, they used from tens to hundreds of ppm as initial concentrations which is far from any realistic indoor air consideration. More recently, other studies were dedicated to various mixtures with ppm level of VOCs. On one hand, these studies showed that VOC mixture may induce an inhibitive effect $[18,19]$. Chen and Zhang tested three mixtures with 2, 3 and 16 VOCs respectively $[20,21]$. They observed an inhibitive mixture effect only with the 16 VOC mixture but no effect with 2 or 3 VOCs. On the other hand, it was also evidenced that mixtures promote degradation. Liang et al. showed such promotion effect on toluene in a ternary mixture with p-xylene and acetone with $240 \mathrm{ppm}$ initial concentrations [22]. This enhancement was interpreted in terms of possible cross reactions between by-products and enhanced reactivity. A few studies get closer to real conditions using VOC mixtures with few hundreds of ppb [23-27]. For instance, Chen et al. observed a competitive adsorption between toluene, ethyl acetate and ethanethiol at $500 \mathrm{ppb}$, resulting in the decrease of the photocatalytic degradation efficiency [24]. These studies with low concentrations and mixtures still need to be completed and moved toward more realistic indoor conditions. More precisely, such studies should include specific investigation of reaction intermediate formation and interaction under mixture conditions.

This study aims at studying photocatalytic oxidation under VOC mixing conditions. Indeed, further than single compound study at ppb level, the present work focuses on the impact of ternary mixture on toluene, decane and trichloroethylene (TCE) photocatalytic degradation at ppb level. Toluene and decane have been selected for (i) their high indoor air occurrences and (ii) the available data on their degradation as single VOCs. TCE is selected for its contrasted chemical structure and reactivity compared to hydrocarbon and the possible cross-reactivity it may induce. The experimental setup used is the one described by Debono et al. for single toluene and decane PCO [5,6]; thus it allows proper comparison between single compound and mixture experiments. Investigations are focused on the impact of the aforementioned VOC ternary mixture on photocatalytic oxidation at the ppb range compared to single VOC treatments. First, the impact is evaluated through the primary VOC removal kinetics. Second, the impact of ternary mixture on reaction intermediates is assessed. Finally, the mineralization of ternary mixture and single VOCs are compared.

\section{Experimental}

Experimental set-up can be divided into three parts: (i) a ppb level VOC generation system, (ii) a 120 L Pyrex photocatalytic batch reaction chamber, (iii) analytical systems for gas phase characterization at ppb levels. This set-up was formerly described in previous papers $[5,6]$ and a general scheme is reported in Fig. 1. Air used for all experiments is supplied by a zero-air generator (Claind AZ 2020) coupled with a PSA (Pressure Swing Absorption) air purifying system. The first step to obtain pure air consists in mineralizing organic compounds present in the 6 bar compressed air using a thermal catalytic treatment unit (zero-air generator). At the outlet of the first step, the level of total VOCs in the gas stream is lower than 10 ppt. The second step consists in removing $\mathrm{CO}, \mathrm{CO}_{2}$ and moisture from the gas stream by sequential absorption under 5 bar. At the outlet of the second step, less than $10 \mathrm{ppb}$ of $\mathrm{CO}_{2}, 80 \mathrm{ppb}$ of $\mathrm{CO}$ and $10 \mathrm{ppm} \mathrm{H}_{2} \mathrm{O}$ are monitored in the gas stream using Infrared Fourier Transform spectroscopy (section 2.3). The obtained air is called zero-air.

\subsection{VOC generation system}

In order to generate accurate concentrations of VOCs in air from 1 to $1000 \mathrm{ppb}$, an appropriate VOC generator system has been developed. Pure liquid toluene, decane and TCE are supplied by Sigma-Aldrich. $300 \mathrm{~mL}$ of liquid individual VOCs or mixture are prepared and placed in a stainless steel pressurized $1 \mathrm{~L}$ tank. The pressure of helium in the tank ranges from 1.1 to 1.3 bar. The liquid VOC flow is regulated from 0 to $200 \mathrm{mg} \mathrm{h}^{-1}$, using a Bronkhorst liquid mass flow controller placed downstream the tank. The liquid is vaporized and mixed with zero air. A fraction of the gas stream obtained is diluted twice with zero air with appropriate ratios in order to reach the targeted concentrations. At the outlet of the generation system, VOC concentrations are tuned from 1 to $1000 \mathrm{ppb}$ with an accuracy of $20 \%$. Since moisture is lower than $10 \mathrm{ppm}$, in order to work with $50 \%$ relative humidity $(\mathrm{RH})$, the air stream containing VOCs is mixed with an equivalent zero air flow previously humidified. Humidity level is checked with a Testo hygrometer characterized by an uncertainty of $2 \%$.

VOCs have been generated (i) individually and (ii) in an equimolar ternary mixture. In the rest of the paper, "single VOC" experiments refer to the individual degradation of toluene, decane or TCE; "ternary mixture" experiments refer to the degradation of the equimolar mixture of toluene, decane and TCE.

\subsection{Photocatalytic reaction chamber}

The photocatalytic reaction chamber consists in a $120 \mathrm{~L}$ Pyrex reactor, which can be kept in the dark or illuminated by nine PLL-40 Philips UV-lamps. The emission band of the lamp in the UV range is centered on $365 \mathrm{~nm}$. No wavelengths lower than $350 \mathrm{~nm}$ are emitted. The resulting UV photon flux is characterized using a SolaCheck photoradiometer at 70 different points of the reaction chamber. The photon flux is homogeneous in the whole reaction chamber including the photocatalyst surface with an average of $10 \pm 1 \mathrm{mWcm}^{-2}$. In order to ensure the experiment reproducibility, the reaction chamber is swept with $50 \% \mathrm{RH}$ zero air for $12 \mathrm{~h}$ under UV illumination before each experiment. The photocatalyst used for all experiments is $100 \mathrm{mg}$ of $\mathrm{P} 25$-Degussa $\mathrm{TiO}_{2}$ powder dispersed in the lower part of the reaction chamber. In this study, the photocatalyst is used in powder form in order to avoid any effect of the photocatalyst support.

After cleaning the photocatalyst and the reaction chamber using $50 \% \mathrm{RH}$ zero air and UV light, the system is swept in the dark for $14 \mathrm{~h}$ with an air flow containing the targeted amount of VOCs in order to reach VOC adsorption equilibrium in the reactor. Then, the chamber 


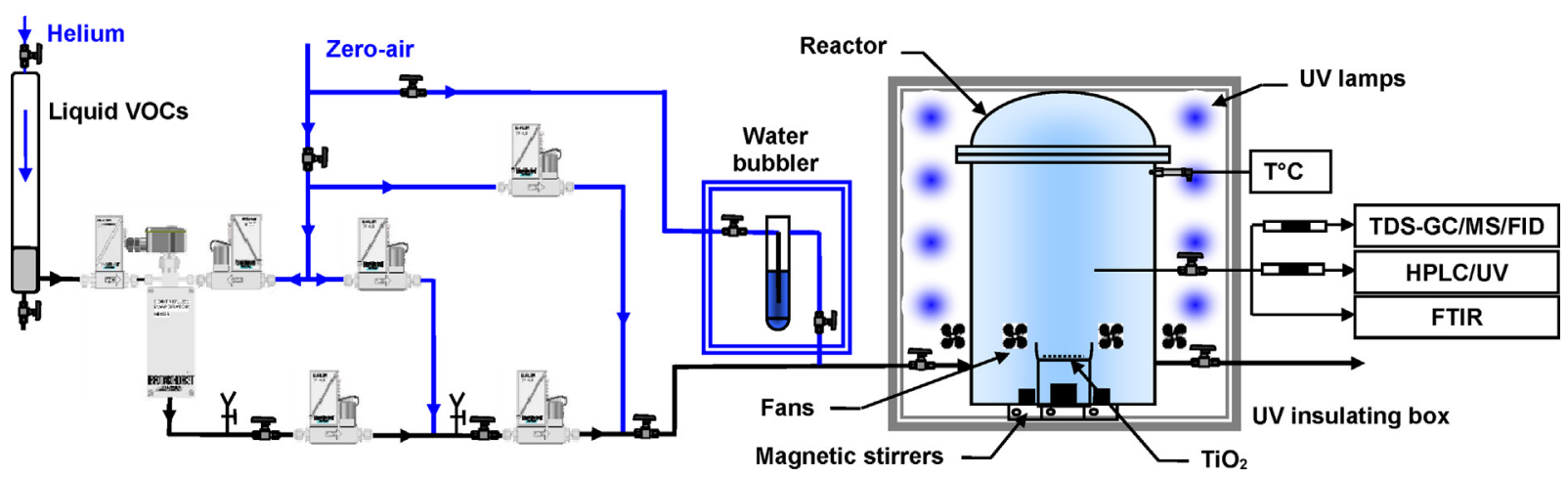

Fig. 1. General experimental set-up.

is closed and VOC concentrations are measured twice. Preliminary static experiments performed in the dark for $48 \mathrm{~h}$ with $800 \mathrm{ppb}$ of toluene have shown that, once the chamber is closed, the VOCs concentration decay is lower than $5 \%$ over $24 \mathrm{~h}$. The start up of UV irradiation defines $\mathrm{t}=0$ for each photocatalytic experiment. Then, the gas phase is characterized all along photocatalytic reaction.

\subsection{Gas phase sampling and analytical devices}

Three main analytical devices are used for a complete gas phase characterization: (i) Gas Chromatography (GC) for VOCs, (ii) derivatization and Liquid Chromatography (HPLC) for carbonyls, and more especially formaldehyde, (iii) Infrared Fourier Transform (FTIR) spectrometry for $\mathrm{CO}$ and $\mathrm{CO}_{2}$.

In order not to significantly modify the pressure inside the batch reactor during the photocatalytic reaction, less than $10 \%$ of the total volume (i.e. 12 L) is sampled for analytical purposes. For each GC analysis, $1 \mathrm{~L}$ of gas is sampled by the Gerstel Thermal Desorption System (TDS) with a constant flow rate of 100 $\mathrm{mL} \min ^{-1}$. The sample is first trapped on a multi-sorbent cartridge (CarboPack X + CarboPack B + CarboPack C), then refocused at $-100^{\circ} \mathrm{C}$ on a CarboPack B filled trap called Cooled Injection System (CIS). The GC is equipped with an Agilent DB-5MS capillary column $(60 \mathrm{~m} \times 0.32 \mathrm{~mm} \times 1 \mu \mathrm{m})$. Using a calibrated Y-shaped restriction, the column is connected to two detectors: (i) a Mass Spectrometer (MS) for compound identification, (ii) a Flame Ionization Detector (FID) for compound quantification. Detection limits are lower than 100 ppt for each VOC monitored in this study. Calibrations of the monitored compounds are performed by loading the sampling multi-sorbent cartridges with various known amounts of VOC obtained from certified gas cylinders or from vaporized liquid VOCs mixtures.

Complementary analytical technique is used for formaldehyde: $1 \mathrm{~L}$ of gas is sampled from the reaction chamber through Waters silica cartridges impregnated with 2.4-dinitrophenylhydrazine (DNPH). This reactive sampling enables the derivatization of carbonyls on the cartridges. Then these cartridges are eluted and analyzed by HPLC as described by Coddeville et al. [28]. With this method, the quantification limit of formaldehyde is $10 \mathrm{ppb}$. Monitoring of acetaldehyde is simultaneously performed with HPLC method and GC in order to crosscheck both quantifications which differed by only $15 \%$.

The detection and quantification of $\mathrm{CO}_{2}$ are performed using a Thermo-Electron Fourier Transform Infrared Spectrometer (FTIR) Antaris IGS equipped with a heated $10 \mathrm{~m}$ optical-path length cell and an MCT (Mercury Cadmium Telluride) detector. The level of $\mathrm{CO}_{2}$ in ambient air usually ranges from 350 to $400 \mathrm{ppm}$. This is much higher than the expected formation of $\mathrm{CO}_{2}$ due to the photocatalytic mineralization of the VOCs mixture. The highest total concentration of the three compounds in the experiments is $2.200 \mathrm{ppb}$. Assum- ing that total VOC mineralization could be achieved, the highest $\mathrm{CO}_{2}$ concentration expected in the reaction chamber would remain below $14 \mathrm{ppm}$. This value is dramatically low in comparison to ambient air $\mathrm{CO}_{2}$ concentration. Thus, a PSA (Pressure Swing Adsorption) system is necessary to remove $\mathrm{CO}_{2}$ from the air supplied to the reactor and subsequently decrease $\mathrm{CO}_{2}$ background level to $10 \mathrm{ppb}$ in the reactor. The $\mathrm{CO}_{2}$ free zero air stream produced by PSA system is simultaneously used to feed the VOC generator and to purge the FTIR optical device.

FTIR spectra are collected using Result-3 software with 6 scans per spectrum and a spectral resolution of $0.5 \mathrm{~cm}^{-1}$. The fundamental asymmetric stretch vibration of $\mathrm{CO}_{2}$ in the region $2388-2383 \mathrm{~cm}^{-1}$ is selected for quantification. Calibration curves for $\mathrm{CO}_{2}$ are determined by passing $1 \mathrm{~L} \mathrm{~min}^{-1}$ of standard gas provided and certified by Praxair through the gas-cell. Calibration concentrations are adjusted from 240 ppb to 20 ppm 500 scans are taken per standard spectrum. For calibration curves and quantitative data processing, TQ-Analyst- 8 software is used. The detection limits are evaluated as twice the Signal/Noise ratio in the region of interest and are $10 \mathrm{ppb}$ for $\mathrm{CO}_{2}$.

\section{Results and discussion}

\subsection{Comparison of single and mixture VOC degradations: 50 - $300 \mathrm{ppb}$}

Photocatalytic degradation profiles of toluene, decane and TCE have been determined as single compounds as well as in ternary mixture. Initial individual VOC concentrations have been varied from ca. 50 to ca. $300 \mathrm{ppb}$ under $50 \% \mathrm{RH}$ and $23^{\circ} \mathrm{C}$ which is compliant with most indoor conditions. First, toluene and decane behavior are presented and discussed and then TCE specific behavior is reported.

\subsubsection{Mixture effect on toluene and decane photocatalytic degradation}

Toluene and decane removal profiles, with $52 \pm 3$ ppb initial concentrations, are represented in Fig. 2. When degraded as single VOCs, as well as in ternary mixture, toluene and decane are characterized by mono-exponential decay profiles (Fig. 2). This temporal variation, typical of pseudo-first order kinetic, is established by (i) the linear temporal variations of $\ln \left(C_{0} / C\right)$ reported in Fig. 3 and (ii) the linear variation of $\ln (d C / d t)$ as a function of $\ln (C)$ (Fig. 4) with typical slope of $n=1.07 \pm 0.1$, corresponding to the reaction order. Interestingly, pseudo first order kinetic is similarly observed when toluene and decane are degraded as single compounds as well as in ternary mixture at ppb level.

Even if the kinetic order remains similar at ppb level between single and mixture degradations, it has to be noted that reaction constants differ. Indeed, it can be derived from Fig. 3 that reac- 


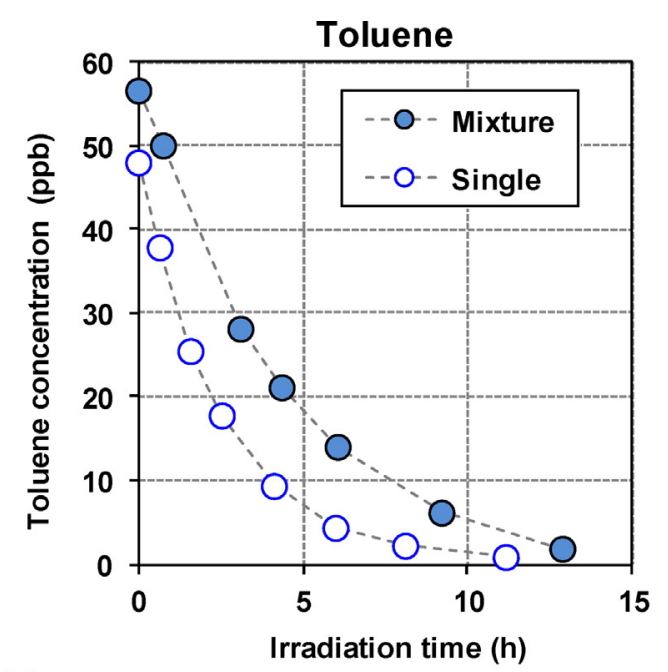

(a)

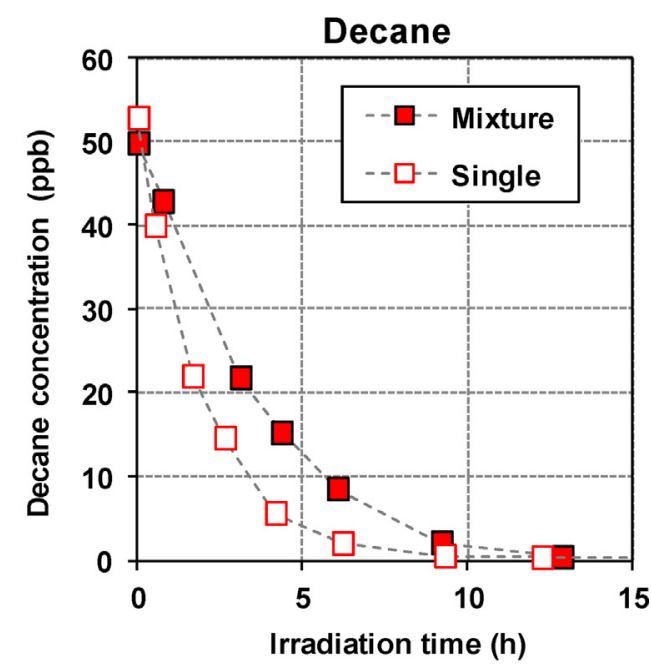

(b)

Fig. 2. Temporal evolutions of (a) toluene and (b) decane concentrations during their photocatalytic oxidations as single compounds and ternary mixture with $52 \pm 3$ ppb individual initial VOC concentrations; $\mathrm{RH}=50 \% ; \mathrm{T}=23^{\circ} \mathrm{C}$.
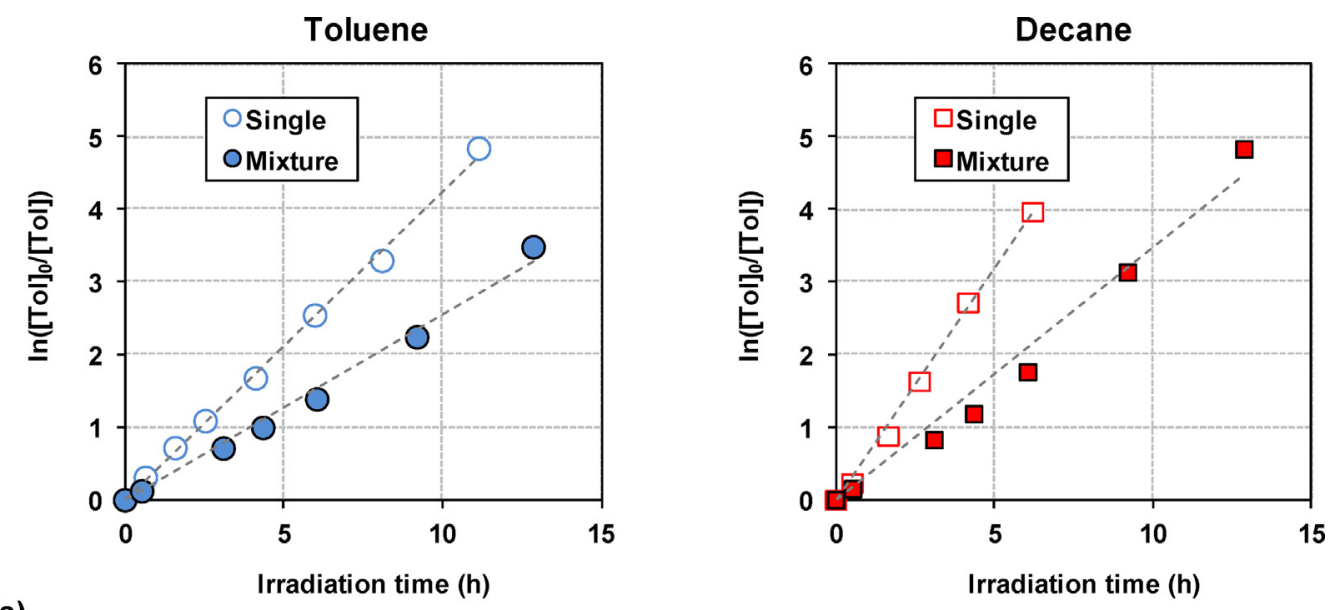

(a)

(b)

Fig. 3. Temporal evolutions of (a) $\ln \left(\left[\mathrm{Tol}_{0} /[\right.\right.$ Tol] $)$ for toluene and (b) $\ln \left([\mathrm{Dec}]_{0} /[\mathrm{Dec}]\right)$ for decane during their photocatalytic oxidations as single compounds and ternary mixture with $52 \pm 3 \mathrm{ppb}$ individual initial VOC concentrations; $\mathrm{RH}=50 \% ; \mathrm{T}=23^{\circ} \mathrm{C}$.

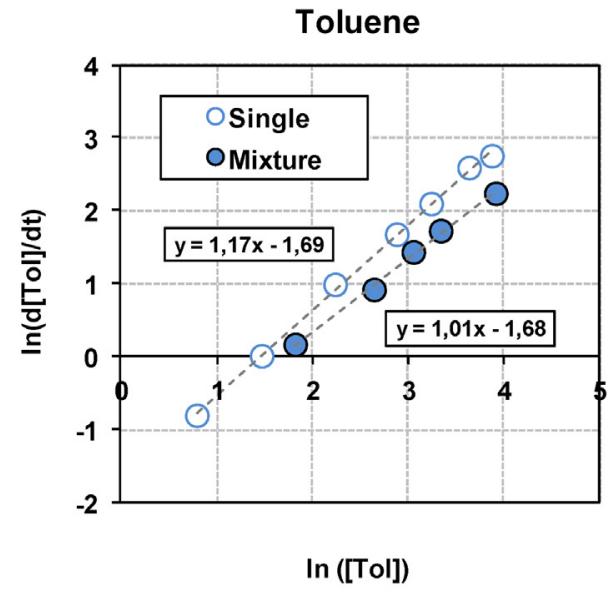

(a)

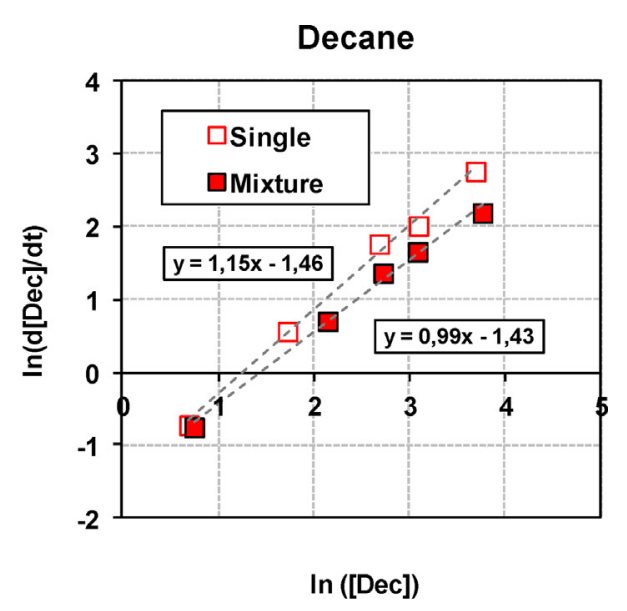

(b)

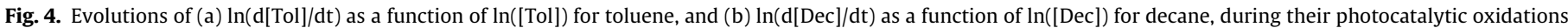
as single compounds and ternary mixture with $52 \pm 3 \mathrm{ppb}$ individual initial VOC concentrations; $\mathrm{RH}=50 \%$; $\mathrm{T}=23^{\circ} \mathrm{C}$. 


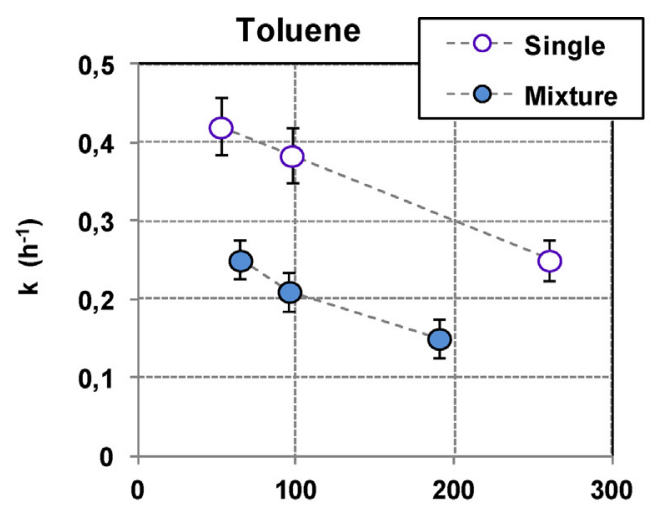

(a)

[Tol] $(\mathbf{p p b})$

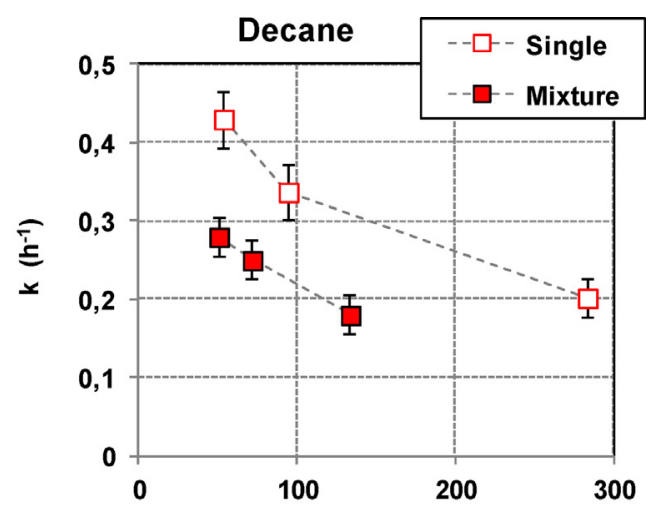

$[\mathrm{Dec}]_{0}(\mathrm{ppb})$

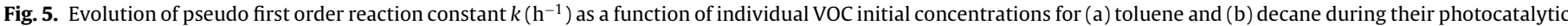
oxidations as single compounds and in ternary mixtures considering a pseudo first order reaction $(n=1) ; \mathrm{RH}=50 \%$; T $=23^{\circ} \mathrm{C}$.

tion constants drop from $0.41 \mathrm{~h}^{-1}$ (toluene) and $0.44 \mathrm{~h}^{-1}$ (decane), for single degradations, to $0.22 \mathrm{~h}^{-1}$ (toluene) and $0.29 \mathrm{~h}^{-1}$ (decane) for mixture degradations. Further experiments have been achieved varying initial individual and mixture VOC concentrations from 50 to $300 \mathrm{ppb}$. Corresponding values of pseudo-first order reaction rates have been similarly determined from the slopes of $\ln \left(C_{0} / C\right)=f(t)$ plots; obtained values are reported in Fig. 5 as a function of initial individual concentrations of toluene (a) and decane (b).

Fig. 5 clearly shows that reaction constants of toluene and decane decrease when VOC initial concentrations increase. Similar trends have been formerly reported in the literature [6,17,29-31]. This behavior is mostly described by Langmuir-Hinshelwood law, encompassing in the kinetic model the various steps of the reaction mechanism, including the adsorption of reactants onto the catalyst surface. The dependence of kinetic constants with initial concentration appears to be emphasized by the low concentration experiments. It also reminds that it is an approximation to model each degradation experiment by a pseudo first order rate law. However, this behavior is identically reported for both single VOCs and ternary mixture. Interestingly, Fig. 5 shows that $k$ values are systematically from 1.5 to 2 times lower for ternary mixture than for single VOCs. In first approach; this behavior would indicate that individual degradations of decane and toluene are significantly inhibited by the presence of other VOCs mixed in the ternary mixture even under ppb level indoor air concentrations.

In order to understand further the correlation between VOC mixture and reaction kinetic at ppb level, the impact of global VOC load on reaction constants has been assessed. Thus, $k$ values of toluene and decane have been plotted as a function of corresponding total initial VOC concentrations in the reactor (Fig. 6). As reported on Fig. 6, initial total VOC concentration appears as a relevant descriptor to compare toluene and decane reaction constants. Indeed, under our experimental conditions, photocatalytic degradations of toluene and decane performed with similar total initial concentrations of VOCs are noticeably characterized by analogous reaction constants, irrespectively of (i) the VOC diversity and (ii) the individual initial concentrations of degraded VOCs. For instance, the single degradation of $273 \mathrm{ppb}$ of decane is characterized by the same reaction constant than the mixture degradation of toluene, decane and TCE with ca. $80 \mathrm{ppb}$ of each, corresponding to an equivalent initial total VOC load in the reactor (Fig. 6). Subsequently, the total initial VOC concentration can be considered as a relevant descriptor for toluene and decane ppb reactivity, and mixture effect could mostly be understood as a concentration effect regarding these VOCs.

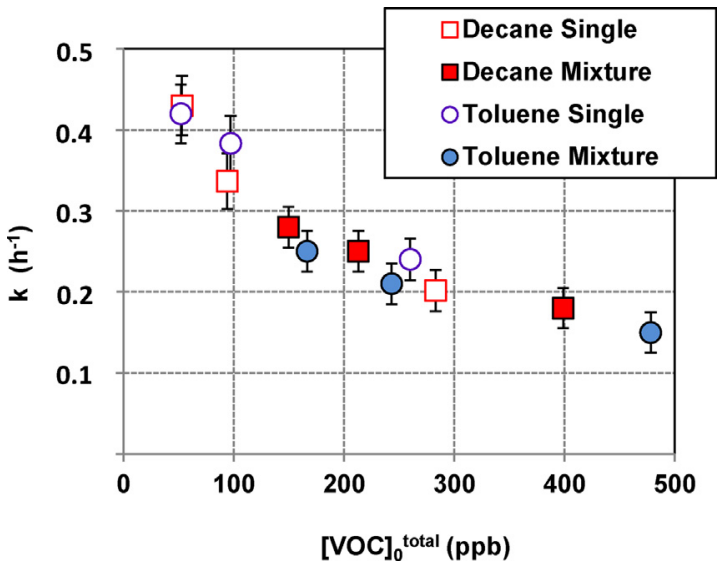

Fig. 6. Evolution of pseudo-first order reaction constant $k\left(\mathrm{~h}^{-1}\right)$ as a function of total initial VOC concentration ( $\mathrm{ppb}$ ) during decane, toluene and ternary mixture photocatalytic oxidations considering a pseudo first order reaction $(n=1) ; \mathrm{RH}=50 \%$; $\mathrm{T}=23^{\circ} \mathrm{C}$.

\subsubsection{Mixture effect on TCE degradation}

As formerly reported by Nishikiori et al. and Hegedüs and Dombi [32,33], TCE photocatalytic degradation does not follow a pseudo-first order kinetic because of generated $\mathrm{Cl}^{\circ}$ radical inducing secondary reactivity. Typical degradation profiles of TCE obtained in this work are reported on Fig. 7 (a). The specific reactivity of chlorinated VOCs along photocatalytic oxidation tends to enhance the VOC degradation rate with irradiation time. This behavior is confirmed by results reported on Fig. 7 on ppb concentration range. However, it has to be noticed that ternary mixture considerably impacts TCE degradation profile compared to single degradation. The inhibitive effect of mixture on TCE removal can be evaluated through TCE degradation rate temporal profiles as calculated and reported on Fig. 7 (b). When degraded as single VOC, TCE degradation rate rises up to $20 \mathrm{ppbh}^{-1}$ within $3 \mathrm{~h}$ and decreases afterward because of VOC depletion. However, in the presence of ternary mixture, TCE maximum degradation rate is limited to $4.5 \mathrm{ppbh}^{-1}$ and this value is reached at least within $7.5 \mathrm{~h}$.

Two hypotheses can be proposed to infer the hindering of TCE removal kinetic under ternary mixture: a first hypothesis could be related to reactivity, a second one to adsorption considerations.

(i) The first hypothesis would rely on the consumption of a significant fraction of generated reactive chlorinated radicals by toluene and decane. Assuming that the increase in TCE degradation rate is mostly related to the production of chlorinated 


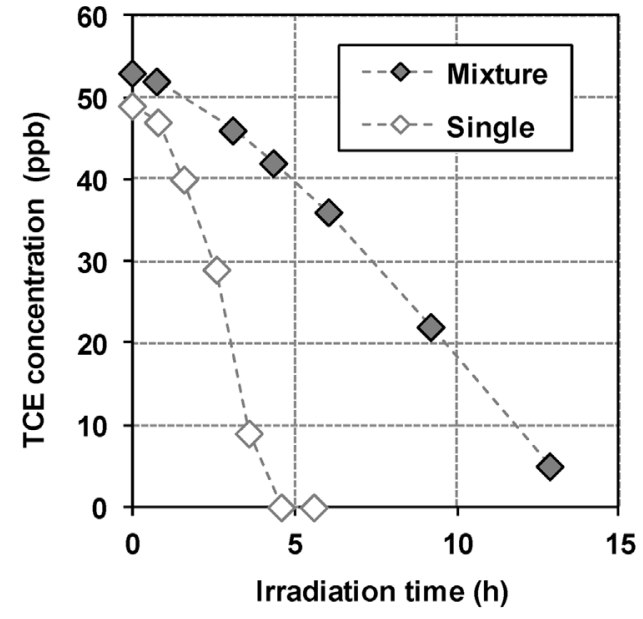

(a)

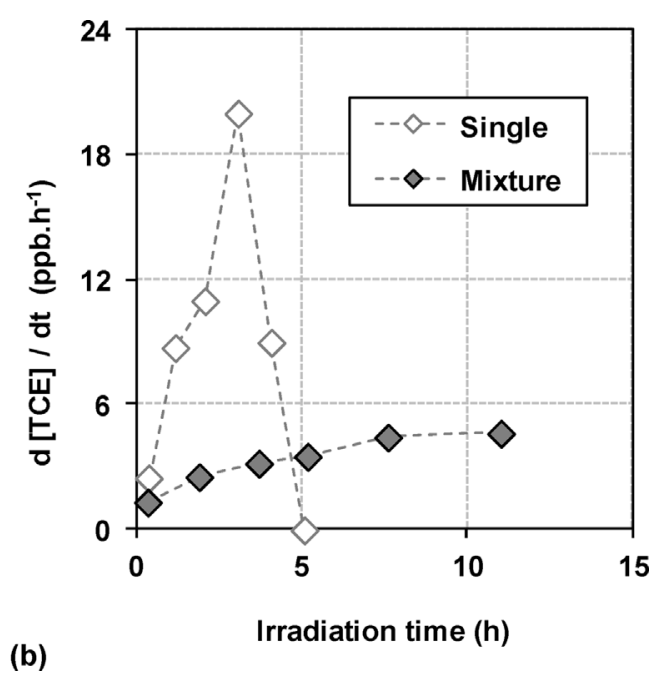

(b)

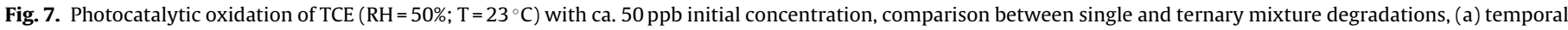
evolution of TCE concentrations, (b) temporal evolution of TCE degradation rate d[TCE]/dt.

reactive species, the proposed hypothesis could be confirmed by (i) an increase in the abatement of other VOCs due to $\mathrm{Cl}^{\circ}$ induced side-reactivity and/or (ii) the monitoring of typical toluene and decane reaction intermediates unexpectedly containing chlorine atoms in their structure. As reported in Section 3.1.1, no increment in toluene and decane abatement is noticed when these VOCs are degraded in mixture, suggesting that $\mathrm{Cl}^{\circ}$ radicals do not promote their degradation. Regarding potential $\mathrm{Cl}^{\circ}$ induced cross-reactivity between reaction intermediates, this point is further addressed in Section 3.2.

(ii) The second hypothesis would rely on the competitive adsorption between VOCs introduced as ternary mixture to access the surface of the photocatalyst. Indeed, the inhibitive effect of VOC mixtures was previously reported by Chen et al. [24] using an equimolar ternary mixture of $500 \mathrm{ppb}$ toluene, ethyl acetate and ethanethiol. Authors connected the mixture impact on VOCs to respective adsorption capacities of VOCs onto the photocatalyst. In the present work, the decrease in degradation rate is more significant for TCE than for toluene and decane, and TCE is the most volatile VOC of the mixture. In spite of the fact that deeper determination of the sorption parameters would be required to propose reliable conclusions to that regard, this point is further discussed in Section 3.3.

\subsection{Mixture effect on reaction intermediates: 50-300 ppb}

Beside primary VOC removal monitoring, reaction intermediates have been characterized during single as well as ternary mixture degradations. Table 1 lists the 21 reaction intermediates detected and quantified during each photocatalytic oxidation of single VOCs and of ternary mixture with initial individual concentrations ranging from 50 to $280 \mathrm{ppb}$ for single degradations and from 50 to $170 \mathrm{ppb}$ for mixture degradation.

\subsubsection{Reaction intermediates monitored along single VOC treatment}

As reported in Table 1, toluene, decane and TCE single photocatalytic oxidations respectively lead to 11,13 and 4 different reaction intermediates monitored in the gas phase. Some intermediates are specific of the oxidized primary VOC, for instance, (i) aromatics for toluene, (ii) decenes and decanones for decane and (ii) chlorinated VOCs for TCE. These specific intermediates are produced in the first steps of the oxidation process. Their temporal profile attest they are mostly primary reaction intermediates. Some other interme- diates are common to toluene and decane; they consist in light carbonyls corresponding to further advancement of the oxidation process and most of them are secondary reaction intermediates. Reaction intermediates identified for toluene and decane degradations were formerly reported and used to determine reaction pathways of these VOCs [5,6].

\subsubsection{Reaction intermediates and ternary mixture treatment}

During ternary mixture degradation as well as toluene and decane single degradations, reaction intermediates characterized by the highest concentrations are formaldehyde and acetaldehyde. This result is consistent with previous studies reporting the formation of reaction intermediates during photocatalytic oxidation of VOC mixtures. Hodgson et al. identified formaldehyde, acetaldehyde, and acetone, as major intermediates during the photocatalytic oxidation of 27 primary VOCs [34-36]. Similarly, Sun et al. reported formaldehyde and acetaldehyde as the main reaction intermediates during the photocatalytic air treatment of typical aircraft cabin VOC mixture [37]. Likewise, Tokarek et al. noticed an increase in formaldehyde concentration when testing a commercially available photocatalytic device with an initial mixture of formaldehyde, toluene, limonene and nitrogen oxides [27].

Based on Table 1, the comparison between single and mixture degradations evidences that two reaction intermediates are specifically monitored during mixture degradations: chlorobenzene and 1.1-dichloroacetone. The formation of these species is highly interesting since they necessarily proceed from reactions between intermediates formed from TCE and other primary hydrocarbons. More precisely, chlorobenzene originates from the reaction between a benzyl radical produced by toluene degradation with a chlorine radical generated from TCE oxidation. Similarly, 1,1-dichloroacetone proceeds from the reaction between a $\mathrm{HCCl}_{2}{ }^{\bullet}$ radical and acetaldehyde respectively originating from TCE and toluene or decane decomposition. The formerly proposed hypothesis suggesting possible reactivity between (i) chlorine radicals formed from TCE and (ii) other initial VOCs and/or their reaction intermediates is therefore favoured. Indeed, along their degradation, reactive side-products of toluene and decane may contribute to the consumption of reactive chlorine containing species produced from TCE degradation. A similar phenomenon was formerly reported by Young et al. between toluene and TCE binary mixture, leading to the production of chloromethylbenzene. However, initial concentrations were in the range $50-170 \mathrm{ppm}$ [38]. Our present work highlights the fact that reaction intermediate cross-reactivity 
Table 1

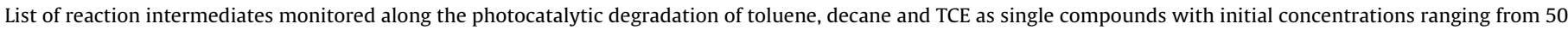
to $280 \mathrm{ppb}$, and as ternary mixture with equimolar individual initial concentrations ranging from 50 to $170 \mathrm{ppb}$.

\begin{tabular}{|c|c|c|c|c|c|}
\hline & & Single toluene [5] & Single decane [6] & Single TCE & Ternary mixture \\
\hline \multirow[t]{6}{*}{ Aldehydes } & Formaldehyde & $\sqrt{ }$ & $\sqrt{ }$ & & $\sqrt{ }$ \\
\hline & Acetaldehyde & $\sqrt{ }$ & $\sqrt{ }$ & & $\sqrt{ }$ \\
\hline & Acrolein & $\sqrt{ }$ & $\sqrt{ }$ & & $\sqrt{ }$ \\
\hline & Propanal & $\sqrt{ }$ & $\sqrt{ }$ & & $\sqrt{ }$ \\
\hline & Butanal & & $\sqrt{ }$ & & $\sqrt{ }$ \\
\hline & Pentanal & $\sqrt{ }$ & $\sqrt{ }$ & & $\sqrt{ }$ \\
\hline \multirow[t]{4}{*}{ Ketones } & Acetone & $\sqrt{ }$ & $\sqrt{ }$ & & $\sqrt{ }$ \\
\hline & MVK & $\sqrt{ }$ & $\sqrt{ }$ & & $\sqrt{ }$ \\
\hline & Butanone & $\sqrt{ }$ & $\sqrt{ }$ & & $\sqrt{ }$ \\
\hline & x-decanones & & $\sqrt{ }$ & & $\sqrt{ }$ \\
\hline \multirow[t]{3}{*}{ Aromatic } & Benzene & $\sqrt{ }$ & & & $\sqrt{ }$ \\
\hline & Benzaldehyde & $\sqrt{ }$ & & & $\sqrt{ }$ \\
\hline & $\mathrm{m}+\mathrm{p}$-cresol & $\sqrt{ }$ & & & $\sqrt{ }$ \\
\hline \multirow[t]{2}{*}{ Alcohols } & Ethanol & & $\sqrt{ }$ & & $\sqrt{ }$ \\
\hline & Isopropanol & & $\sqrt{ }$ & & $\sqrt{ }$ \\
\hline Alkenes & x-decenes & & $\sqrt{ }$ & & $\sqrt{ }$ \\
\hline \multirow[t]{3}{*}{ Chlorinated } & Chloromethane & & & $\sqrt{ }$ & $\sqrt{ }$ \\
\hline & Dichloromethane & & & $\sqrt{ }$ & $\sqrt{ }$ \\
\hline & Trichloromethane & & & $\sqrt{ }$ & $\sqrt{ }$ \\
\hline Specific to ternary & Chlorobenzene & & & & $\sqrt{ }$ \\
\hline mixture & 1.1-dichloroacetone & & & & $\sqrt{ }$ \\
\hline
\end{tabular}

can be observed even at ppb levels, i.e. under typical indoor concentrations. However, such species remained among intermediates with the lowest concentrations under our experimental conditions which suggest that the chlorinated species consumption by toluene and decane intermediates stays a minor reaction pathway.

\subsection{Impact of initial concentration increase on mixture degradation: $650-850 \mathrm{ppb}$}

Based on results obtained with individual initial concentrations ranging from 50 to $300 \mathrm{ppb}$, a global slowdown of VOC removal kinetic is observed under ternary mixture. In the case of TCE, this phenomenon could be partly attributed to the consumption of chlorine containing species by other primary VOCs and reaction intermediates. However, as suggested in section 3.1.2, sorption considerations may also contribute to the global removal kinetic delay. In order to assess that point further, experiments have been carried out with higher individual initial concentrations ranging from 650 to $850 \mathrm{ppb}$. The selected concentration range aims at (i) emphasizing potential competitive sorption phenomena through an increase of the photocatalyst surface coverage and (ii) remaining at sub-ppm levels in order to be still compliant with indoor air treatment considerations. Indeed, such initial concentration range would correspond to an intense transient indoor pollution event leading to an enhanced solicitation of the photocatalyst.

Degradation profiles represented in Fig. 8 are obtained for (a) single VOC, and (b) ternary mixture degradations. Comparison of temporal profiles evidences that similarly to $50-300 \mathrm{ppb}$ range experiments, ternary mixture considerably impacts the process kinetic on the $650-850 \mathrm{ppb}$ range.

More precisely, toluene and decane removal still follow a pseudo first order reaction kinetic when degraded on 650-850 ppb range as ternary mixture (Fig. 8). However, similarly to lower concentration experiments, their pseudo-first order constants drop from a factor two from single to ternary mixture degradations. Indeed, reaction constants fall from 0.23 and $0.17 \mathrm{~h}^{-1}$ to 0.11 and $0.08 \mathrm{~h}^{-1}$ respectively for decane and toluene. As a consequence, more than $30 \mathrm{~h}$ are required to completely remove decane and toluene when degraded in mixture compared to $15-20 \mathrm{~h}$ as single compounds.

On the $650-850 \mathrm{ppb}$ range, TCE removal profile in mixture is completely modified (Fig. 8). TCE is totally removed from the reactor within $5 \mathrm{~h}$ as single compound, whereas $40 \mathrm{~h}$ are required in

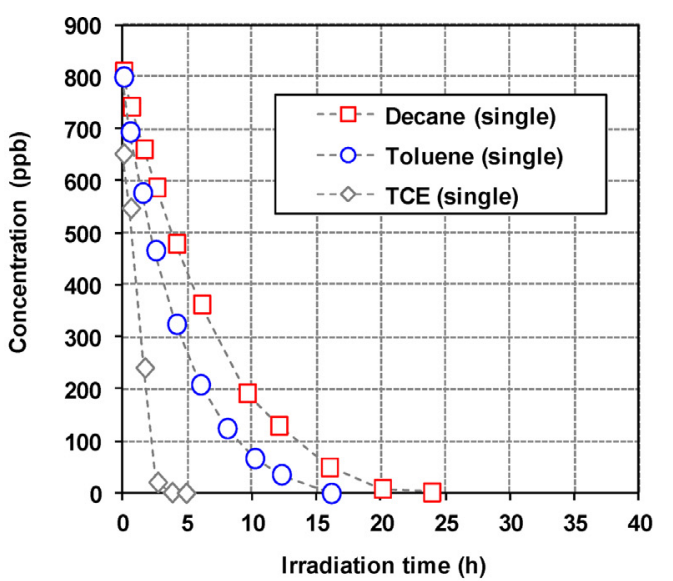

(a)

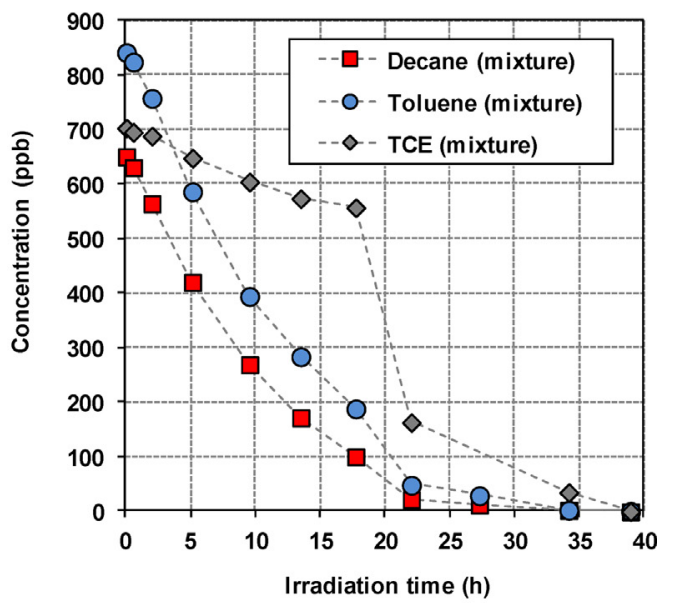

(b)

Fig. 8. Temporal evolutions of toluene, decane and TCE concentrations during their photocatalytic oxidations as (a) single compounds and (b) ternary mixture with individual initial concentrations from 650 to $850 \mathrm{ppb}$; $\mathrm{RH}=50 \%$; $\mathrm{T}=23^{\circ} \mathrm{C}$. 


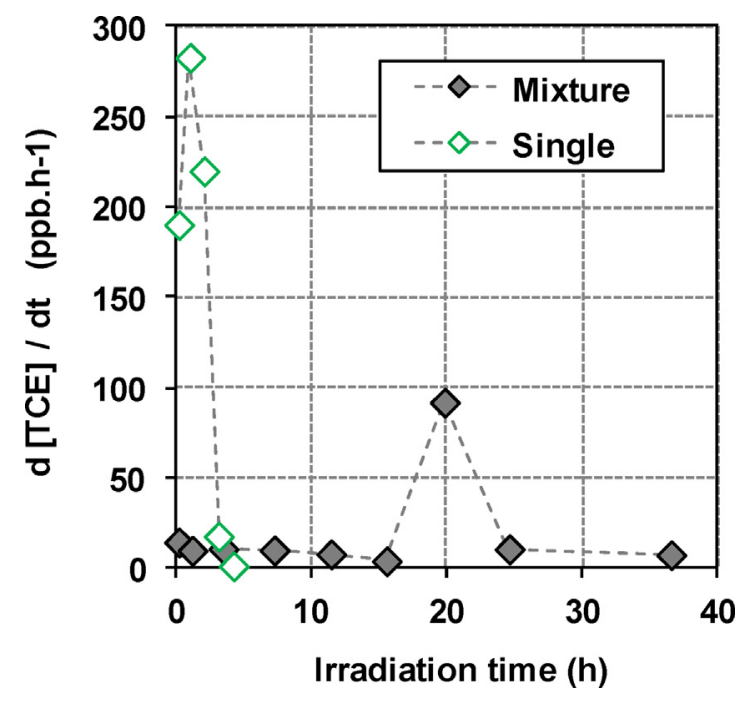

Fig. 9. Temporal evolutions of TCE degradation rate d[TCE]/dt during photocatalytic degradations as single compound and in ternary mixture; $\mathrm{RH}=50 \% ; \mathrm{T}=23^{\circ} \mathrm{C}$.

the ternary mixture. When degraded as single VOC, the comparison of TCE removal rate temporal profiles from Fig. 7 (b) and Fig. 9 indicates that TCE removal kinetics are similar. Maximum TCE removal rates linearly increase with initial concentrations by a factor 14 . However, when degraded in ternary mixture, from 0 to $18 \mathrm{~h}$ irradiation, TCE removal remains weak; indeed, TCE removal rate keeps almost constant on that time range, with an average value of $9.2 \pm 2.2 \mathrm{ppb} \mathrm{h}^{-1}$ (Fig. 9). Beyond $18 \mathrm{~h}$ irradiation, TCE removal rate is abruptly multiplied by 10 and TCE concentration decreases till the complete depletion of the reactant. The sudden removal of TCE can be correlated with the fact that, beyond $18 \mathrm{~h}$, more than $80 \%$ of toluene and $85 \%$ of decane are removed from the gas phase. Such a behavior suggests that primary VOCs could be sequentially, and not simultaneously, removed from the gas phase in spite of the sub-ppm initial concentrations.

The sequential VOC removal phenomenon could be related to the structure of the degraded VOCs and their ability to interact preferentially with the photocatalyst surface. This approach praises on the hypothesis related to competitive adsorption proposed in Section 3.1.2. In 2003, Zorn [39] evidenced similar phenomenon along the degradation of a $600 \mathrm{ppm}$ binary mixture of acetone mixed with ethylene or propene. Alkenes removal is delayed as long as acetone is present in the reaction chamber. This sequential treatment was interpreted in terms of competitive adsorption between alkenes and the ketone. The question of sequential photocatalytic treatment of VOC mixture could be more precisely addressed based on detailed sorption parameter determination under relevant environmental conditions, however only few data are available to that regard, but obtained results on the ppb range clearly motivate this approach in the future.

\subsection{Impact of VOC mixture on mineralization}

Three parameters have to be taken into account to completely characterize photocatalytic performances: (i) the degradation of primary VOCs, (ii) the formation of reaction intermediates, and (iii) the mineralization into $\mathrm{CO}_{2}$. Mineralization attests of the overall process purification efficiency. Subsequently, $\mathrm{CO}_{2}$ concentration has been measured during the photocatalytic oxidation of the ternary mixture as well as single compounds, with initial individual concentrations of VOCs from 650 to $850 \mathrm{ppb}$. Until now, at ppb level, only spare measurements of $\mathrm{CO}_{2}$ for the binary mixture 2propanol/toluene were reported [25]. Continuous measurement of

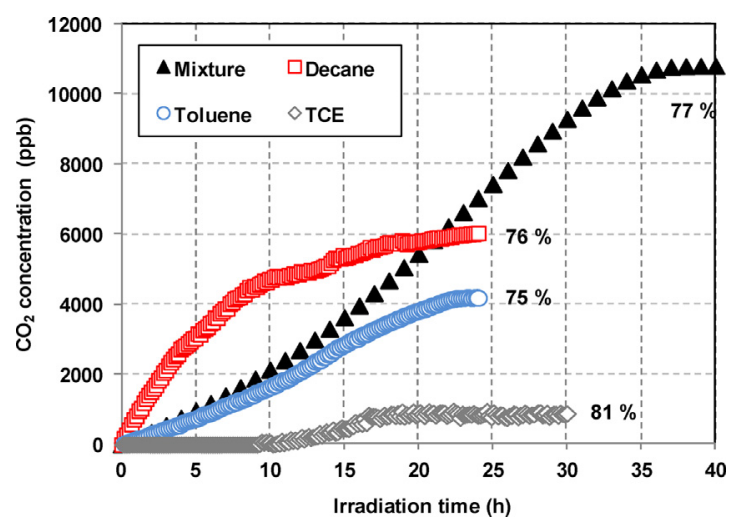

Fig. 10. Temporal evolution of $\mathrm{CO}_{2}$ concentration during the photocatalytic oxidation of toluene, decane and TCE as single compounds and in ternary mixture $\left(\mathrm{C}_{0}{ }^{\mathrm{Tol}}=842 \mathrm{ppb} ; \mathrm{C}_{0}{ }^{\mathrm{Dec}}=651 \mathrm{ppb} ; \mathrm{C}_{0}{ }^{\mathrm{TCE}}=704 \mathrm{ppb}\right) ; \mathrm{RH}=50 \% ; \mathrm{T}=23^{\circ} \mathrm{C}$; percentage values correspond to the respective contributions of stabilized $\mathrm{CO}_{2}$ concentration into the carbon mass balance at the end of the photocatalytic process.

$\mathrm{CO}_{2}$ production along VOC ppb level photocatalytic oxidation was only achieved by Debono et al. with single VOC degradation $[5,6]$. The temporal profiles of $\mathrm{CO}_{2}$ concentration presented here are the first obtained during the photocatalytic oxidation of a VOC mixture on ppb range concentrations.

\subsection{1. $\mathrm{CO}_{2}$ formation during single VOC treatment}

As reported on Fig. 10, single and mixture experiments are characterized by specific $\mathrm{CO}_{2}$ concentration profiles. $\mathrm{CO}_{2}$ profiles related to toluene and decane treatment show similar basic characteristics: (i) $\mathrm{CO}_{2}$ is formed from the very beginning of the treatment and (ii) $\mathrm{CO}_{2}$ concentration increases till an asymptotic value. $\mathrm{CO}_{2}$ monitoring has been performed for any experimental condition till $\mathrm{CO}_{2}$ concentration gets stable, attesting of the utmost mineralization advancement of the photocatalytic process. In the case of toluene and decane, beyond $25 \mathrm{~h}$ of irradiation, maxima of 75 and $76 \%$ of initial VOCs are respectively converted into $\mathrm{CO}_{2}$. However, $\mathrm{CO}_{2}$ concentration profile from toluene photocatalytic oxidation has a sigmoid shape while decane one is logarithmic. These issues have been formerly discussed for single VOCs $[5,6]$. The sigmoid profile for toluene mineralization was related to the evolution of adsorbed and degraded reaction intermediates along the reaction advancement [5].

Regarding TCE, $\mathrm{CO}_{2}$ production totally differs from decane and toluene. $\mathrm{CO}_{2}$ is not formed during the first $10 \mathrm{~h}$ of treatment; however, beyond $10 \mathrm{~h}, \mathrm{CO}_{2}$ concentration rapidly increases and reaches its maximum after $18 \mathrm{~h}$, leading to a final TCE mineralization rate of $81 \%$. This behavior, characterized by a significant mineralization delay, suggests that TCE is primarily converted into reaction intermediates which are consecutively converted into $\mathrm{CO}_{2}$. Considering the nature and the levels of monitored TCE reaction intermediates, it can be suggested that such a mineralization delay could be attributed to adsorbed and stable surface intermediates.

\subsection{2. $\mathrm{CO}_{2}$ formation during ternary mixture treatment}

During ternary mixture photocatalytic oxidation, $\mathrm{CO}_{2}$ formation profile is close to toluene sigmoid one, suggesting that primary reaction intermediates produced along the first $15 \mathrm{~h}$ of treatment are less readily mineralized than the one formed at higher advancements. Toluene or TCE reaction intermediates could be responsible for that behavior. Nevertheless, $\mathrm{CO}_{2}$ is formed since the beginning of the irradiation. After $36 \mathrm{~h}$ of treatment, $\mathrm{CO}_{2}$ concentration gets stabilized corresponding to $77 \%$ of the reaction carbon mass balance. Similar maximum mineralization rates are obtained for single VOCs. Thus, despite the differences of $\mathrm{CO}_{2}$ formation profiles, same mineralization rates can be reached whether VOC are 


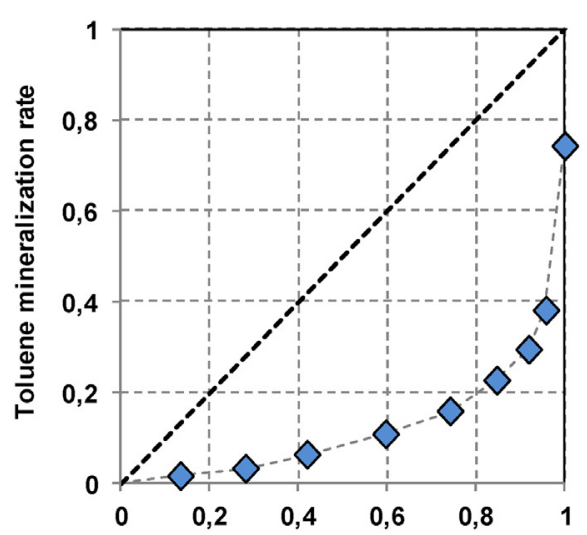

(a)

Toluene conversion rate

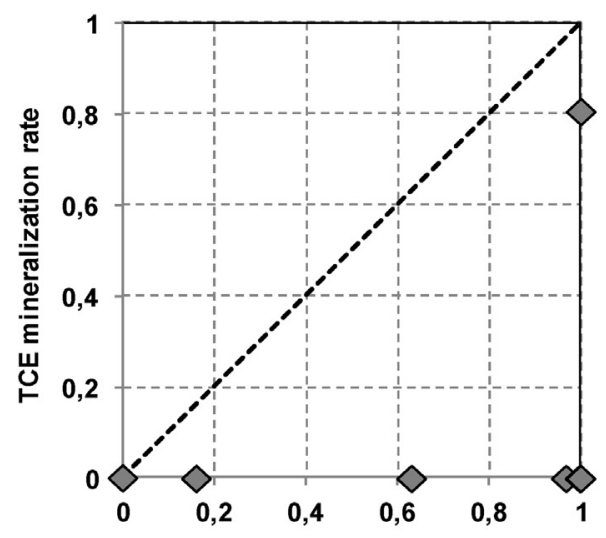

(c)
TCE conversion rate

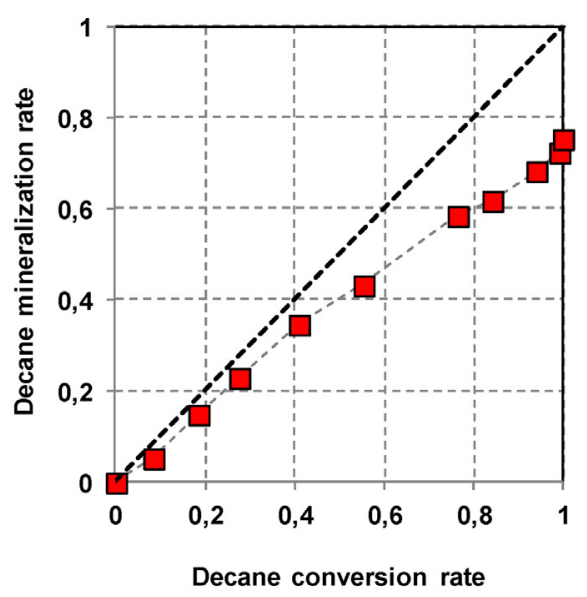

(b)

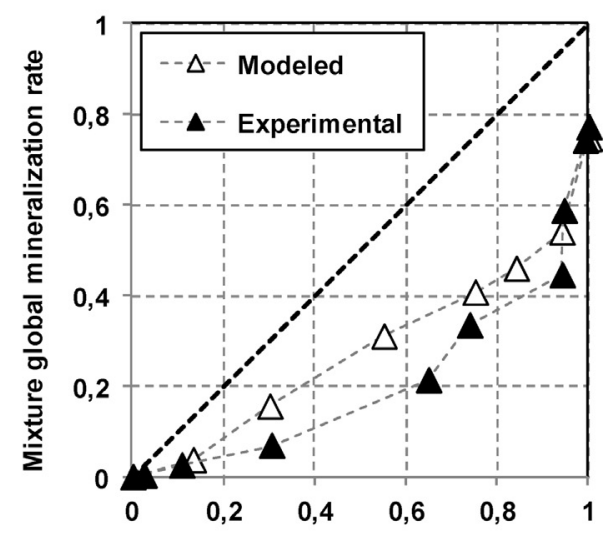

(d)

Mixture global conversion rate

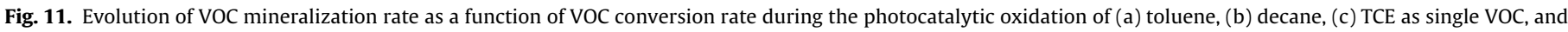
(d) ternary mixture; $\mathrm{RH}=50 \% ; \mathrm{T}=23^{\circ} \mathrm{C}$

degraded as single compound or in ternary mixture at ppb level. This result differs from former observations reported at ppm levels. Indeed, Moulis and Krysa [18] reported a significant mineralization drop, from 70 to $25 \%$, during the degradation of hexane, butyl acetate and toluene, with respective concentrations of 8500, 3200 and $860 \mathrm{ppm}$, when these primary VOCs were treated as a mixture. Authors mentioned a deactivation of the photocatalyst mostly due to toluene reaction intermediates. Our experiments evidence that (i) global mineralization performances are kept constant with mixture degradation at ppb level and (ii) former conclusions from mineralization studies performed on the ppm range cannot be directly transferred to ppb range due to surface saturation issues.

\subsubsection{VOC degradation vs. VOC mineralization at ppb level}

In order to evaluate the promptness of the photocatalyst to convert removed VOCs into $\mathrm{CO}_{2}$, VOC mineralization rates are plotted as a function of the VOC removal rate. Corresponding plotting are reported on Fig. 11 for single VOCs treatment (a, b and c) and ternary mixture treatment (d). If VOCs were instantaneously converted into $\mathrm{CO}_{2}$, plotted data would fit with the dotted diagonal line. Such a behavior was formerly reported by Thevenet et al. with the photocatalytic oxidation of acetylene [40]. Nevertheless most of photocatalytic oxidation processes involve various oxidation steps and reaction intermediate production, subsequently leading to a changeable gap between plotted data and diagonal. This gap is an indicator of the VOC mineralization delay corresponding to the transient formation of reaction intermediates.
Fig. 11 evidences that each VOC is characterized by a specific profile.

- Decane profile is the closest from the diagonal, which means that it is the fastest VOC to be mineralized along its degradation. Indeed, reaction intermediates of decane are oxygenated aliphatic compounds, which are rapidly degraded by photocatalytic process [6].

- Toluene initial mineralization rate is low compared to removal rate, but it gradually increases until total conversion of toluene. This behavior is consistent with the sigmoid shape profile of $\mathrm{CO}_{2}$ concentration along toluene oxidation (Fig. 10). Indeed, primary reaction intermediates formed at the beginning of toluene oxidation are aromatic compounds, which could even condense to form polyaromatic structures [5,38]. The degradation of these aromatic compounds is slow due to aromatic ring, whereas secondary reaction intermediates are aliphatic and more easily mineralized into $\mathrm{CO}_{2}[5]$.

- TCE mineralization does not occur until TCE has totally been converted. Thus TCE is totally removed from the gas phase before its mineralization starts, leading to the very specific profile of TCE on Fig. 11. This behavior confirms that stable reaction intermediates are produced along TCE photocatalytic oxidation, and undeniably stored on the photocatalyst surface.

Regarding ternary mixture, the monitored profile is reported on Fig. 11 (d) as "Experimental" data. Fig. 11 (d) also proposes a comparison between "Experimental" data and "Modeled" profile. The 
"Modeled" profile is obtained by the convolution of corresponding single VOC plots weighted by the number of carbon atoms in each VOC. This comparison evidences that photocatalytic mineralization promptness of the ternary mixture is slightly lower than what could have been expected from the linear convolution of individual VOC behaviors. Once again, ternary mixture degradation may tend to hinder to some extent the global activity of the photocatalytic process, then, performances observed under mixture degradation could be directly extrapolated from individual VOC characterization even when working at ppb level concentrations.

\section{Conclusion}

Based on the detailed investigation of the ppb level photocatalytic oxidation of an equimolar ternary mixture of VOCs compared with the corresponding single compound degradations, effective conclusions have been obtained regarding the three main performance criteria of photocatalytic process: primary VOC removal kinetic, reaction intermediates formation and mineralization.

(i) The photocatalytic removal kinetics of decane and toluene are decreased by VOC mixture effect, and this phenomenon can be interpreted in terms of total initial concentration of VOCs, showing that even at ppb level, the VOC load in the reactor may directly affect the removal performances. Trichloroethylene removal kinetic is impacted by the VOC mixture in a stronger way. This result can be interpreted in terms of photocatalyst surface accessibility i.e. competitive sorption. Experiments at higher ppb levels interestingly evidenced possible sequential treatment of VOCs requiring deeper and detailed investigations of VOC sorption parameters onto $\mathrm{TiO}_{2}$.

(ii) Reaction intermediates produced by single VOC photocatalytic oxidation are similarly observed along mixture treatment. Beside, this work interestingly evidenced the formation of specific VOCs originating from reaction intermediate crossreactivity. Such phenomenon, even if it remains a minor pathway, suggests that multiple VOC degradation may lead to a wider diversity of side-product formation than during single VOC treatment, emphasizing the requirement of sideproduct characterization above all when photocatalysis is used for indoor air treatment, and even surface side products for more fundamental approaches.

(iii) For the first time the mineralization of multiple VOC degradation is monitored and compared to the mineralization of single VOCs. This work evidenced the contrasted mineralization abilities of VOCs according to their structures. Moreover, the mineralization of a VOC mixture cannot be directly inferred from single VOC mineralization.

\section{Acknowledgments}

The authors thank (i) the Institut Carnot M.I.N.E.S. for the financial support of the PHOTOCOV project, (ii) Thierry Leonardis and Isabelle Fronval from IMT Lille Douai SAGE for their valuable technical assistance.

\section{References}

[1] World Health Organization, Burden of Disease from Household Air Pollution for 2012, 2014.

[2] M. Ragazzi, P. Tosi, E.C. Rada, V. Torretta, M. Schiavon, Effluents from MBT plants: plasma techniques for the treatment of VOCs, Waste Manag. 34 (2014) 2400-2406, http://dx.doi.org/10.1016/j.wasman.2014.07.026.

[3] F. Thevenet, L. Sivachandiran, O. Guaitella, C. Barakat, A. Rousseau, Plasma-catalyst coupling for volatile organic compound removal and indoor air treatment: a review, J. Phys. Appl. Phys. 47 (2014) 224011, http://dx.doi. org/10.1088/0022-3727/47/22/224011.
[4] J. Mo, Y. Zhang, Q. Xu, J.J. Lamson, R. Zhao, Photocatalytic purification of volatile organic compounds in indoor air: a literature review, Atmos. Environ. 43 (2009) 2229-2246, http://dx.doi.org/10.1016/j.atmosenv.2009.01.034.

[5] O. Debono, F. Thevenet, P. Gravejat, V. Hequet, C. Raillard, L. Lecoq, N. Locoge Toluene photocatalytic oxidation at ppbv levels: kinetic investigation and carbon balance determination, Appl. Catal. B Environ. 106 (2011) 600-608, http://dx.doi.org/10.1016/j.apcatb.2011.06.021.

[6] O. Debono, F. Thévenet, P. Gravejat, V. Héquet, C. Raillard, L. Le Coq, N. Locoge, Gas phase photocatalytic oxidation of decane at ppb levels: removal kinetics, reaction intermediates and carbon mass balance, J. Photochem. Photobiol. Chem. 258 (2013) 17-29, http://dx.doi.org/10.1016/j.jphotochem.2013.02. 022.

[7] T. Guo, Z. Bai, C. Wu, T. Zhu, Influence of relative humidity on the photocatalytic oxidation (PCO) of toluene by $\mathrm{TiO} 2$ loaded on activated carbon fibers: PCO rate and intermediates accumulation, Appl. Catal. B Environ. 79 (2008) 171-178, http://dx.doi.org/10.1016/j.apcatb.2007.09.033.

[8] R.A.R. Monteiro, A.M.T. Silva, J.R.M. Ângelo, G.V. Silva, A.M. Mendes, R.A.R. Boaventura, V.J.P. Vilar, Photocatalytic oxidation of gaseous perchloroethylene over TiO2 based paint, J. Photochem. Photobiol. Chem. 311 (2015) 41-52, http://dx.doi.org/10.1016/j.jphotochem.2015.06.007.

[9] S. Kirchner, Final Report, Observatoire de la Qualité de l'Air Intérieur (OQAI), France, 2007

[10] M. Derbez, B. Berthineau, V. Cochet, M. Lethrosne, C. Pignon, J. Riberon, S. Kirchner, Indoor air quality and comfort in seven newly built, energy-efficient houses in France, Build. Environ. 72 (2014) 173-187, http://dx.doi.org/10. 1016/j.buildenv.2013.10.017

[11] S. Langer, G. Bekö, E. Bloom, A. Widheden, L. Ekberg, Indoor air quality in passive and conventional new houses in Sweden, Build. Environ. 93 (Part 1) (2015) 92-100, http://dx.doi.org/10.1016/j.buildenv.2015.02.004.

[12] C.S. Turchi, D.F. Ollis, Mixed reactant photocatalysis: intermediates and mutual rate inhibition, J. Catal. 119 (1989) 483-496, http://dx.doi.org/10 1016/0021-9517(89)90176-0.

[13] O. d'Hennezel, D.F. Ollis, Trichloroethylene-promoted photocatalytic oxidation of air contaminants, J. Catal. 167 (1997) 118-126, http://dx.doi.org/ 10.1006/jcat.1997.1552.

[14] Y. Luo, D.F. Ollis, Heterogeneous photocatalytic oxidation of trichloroethylene and toluene mixtures in air: kinetic promotion and inhibition, time-dependent catalyst activity, J. Catal. 163 (1996) 1-11, http://dx.doi.org/ 10.1006/jcat.1996.0299.

[15] J. Peral, D.F. Ollis, Heterogeneous photocatalytic oxidation of gas-phase organics for air purification: acetone, 1-butanol, butyraldehyde, formaldehyde, and m-xylene oxidation, J. Catal. 136 (1992) 554-565, http:/ dx.doi.org/10.1016/0021-9517(92)90085-V.

[16] M.L. Sauer, M.A. Hale, D.F. Ollis, Heterogenous photocatalytic oxidation of dilute toluene-chlorocarbon mixtures in air, J. Photochem. Photobiol. Chem. 88 (1995) 169-178, http://dx.doi.org/10.1016/1010-6030(95)04052-H.

[17] M.L. Sauer, D.F. Ollis, Photocatalyzed oxidation of ethanol and acetaldehyde in humidified air, J. Catal. 158 (1996) 570-582, http://dx.doi.org/10.1006/jcat. 1996.0055.

[18] F. Moulis, J. Krýsa, Photocatalytic degradation of several VOCs (n-hexane, n-butyl acetate and toluene) on TiO2 layer in a closed-loop reactor, Catal. Today. 209 (2013) 153-158, http://dx.doi.org/10.1016/j.cattod.2012.10.017.

[19] M.E. Zorn, S.O. Hay, M.A. Anderson, Effect of molecular functionality on the photocatalytic oxidation of gas-phase mixtures, Appl. Catal. B Environ. 99 (2010) 420-427, http://dx.doi.org/10.1016/j.apcatb.2010.05.009.

[20] W. Chen, J. (Jensen) Zhang, Photocatalytic oxidation of multi-Component systems -an investigation using toluene/ethylbenzene, octane/decane/dodecane and formaldehyde/acetaldehyde, J. Adv. Oxid. Technol. 11 (2008) 163-173.

[21] W. Chen, J.S. Zhang, UV-PCO device for indoor VOCs removal: investigation on multiple compounds effect, Build. Environ. 43 (2008) 246-252, http://dx.doi. org/10.1016/j.buildenv.2006.03.024.

[22] W.J. Liang, J. Li, Y.Q. Jin, Photocatalytic degradation of gaseous acetone, toluene, and p-xylene using a TiO2 thin film, J. Environ. Sci. Health Part A Tox. Hazard. Subst. Environ. Eng. 45 (2010) 1384-1390, http://dx.doi.org/10.1080/ 10934529.2010.500925.

[23] C.H. Ao, S.C. Lee, J.Z. Yu, J.H. Xu, Photodegradation of formaldehyde by photocatalyst TiO2: effects on the presences of NO, SO2 and VOCs, Appl. Catal. B Environ. 54 (2004) 41-50, http://dx.doi.org/10.1016/j.apcatb.2004.06.004.

[24] J. Chen, G. Li, Z. He, T. An, Adsorption and degradation of model volatile organic compounds by a combined titania-montmorillonite-silica photocatalyst, J. Hazard. Mater. 190 (2011) 416-423, http://dx.doi.org/10. 1016/j.jhazmat.2011.03.064.

[25] D. Vildozo, R. Portela, C. Ferronato, J.-M. Chovelon, Photocatalytic oxidation of 2-propanol/toluene binary mixtures at indoor air concentration levels, Appl. Catal. B Environ. 107 (2011) 347-354, http://dx.doi.org/10.1016/j.apcatb. 2011.07.035

[26] W.-K. Jo, S.-H. Shin, Photocatalytic decomposition of mobile-source related pollutants using a continuous-flow reactor, J. Environ. Sci. 22 (2010) 460-466, http://dx.doi.org/10.1016/S1001-0742(09)60130-3.

[27] S. Tokarek, B. Barreau, S. Capela, M. Nicolas, F. Maupetit, S. Ritoux, F. Squinazi, G. Guillossou, V. Ezratty, É. Robert-Gnansia, Caractérisation de l'efficacité chimique et particulaire d'un épurateur d'air photocatalytique autonome. Environ. Risques Santé. 10 (2011) 35-45.

[28] P. Coddeville, N. Locoge, J.-C. Galloo, Determination of Organic Compound Levels at Donon Station, Ecole des Mines de Douai, France, 1998. 
[29] C. Raillard, V. Héquet, P.L. Cloirec, J. Legrand, TiO2 coating types influencing the role of water vapor on the photocatalytic oxidation of methyl ethyl ketone in the gas phase, Appl. Catal. B Environ. 59 (2005) 213-220, http://dx.doi.org/ 10.1016/j.apcatb.2005.02.011.

[30] C. Raillard, V. Héquet, P. Le Cloirec, J. Legrand, Kinetic study of ketones photocatalytic oxidation in gas phase using TiO2-containing paper: effect of water vapor, J. Photochem. Photobiol. Chem. 163 (2004) 425-431, http://dx. doi.org/10.1016/j.jphotochem.2004.01.014.

[31] C. Raillard, V. Héquet, P.L. Cloirec, J. Legrand, Photocatalytic oxidation of methyl ethyl ketone over sol-gel and commercial TiO2 for the improvement of indoor air, Water Sci. Technol. 53 (2006) 107-115, http://dx.doi.org/10. 2166/wst.2006.343.

[32] H. Nishikiori, M. Furukawa, T. Fujii, Degradation of trichloroethylene using highly adsorptive allophane-TiO2 nanocomposite, Appl. Catal. B Environ. 102 (2011) 470-474, http://dx.doi.org/10.1016/j.apcatb.2010.12.028.

[33] M. Hegedüs, A. Dombi, Comparative study of heterogeneous photocatalytic decomposition of tetrachloroethene and trichloroethene in the gas phase, Appl. Catal. Gen. 271 (2004) 177-184, http://dx.doi.org/10.1016/j.apcata. 2004.02.057.

[34] A.T. Hodgson, H. Destaillats, D.P. Sullivan, W.J. Fisk, Performance of ultraviolet photocatalytic oxidation for indoor air cleaning applications, Indoor Air. 17 (2007) 305-316, http://dx.doi.org/10.1111/j.1600-0668.2007.00479.x.
[35] A.T. Hodgson, D.P. Sullivan, W.J. Fisk, Evaluation of Ultra-violet Photocatalytic Oxidation (UVPCO) for Indoor Air Applications: Conversion of Volatile Organic Compounds at Low Part-per-billion Concentrations, Lawrence Berkeley Natl. Lab., 2005, Accessed 11 June 2015 http://escholarship.org/uc/item/49n5x4px.

[36] A.T. Hodgson, D.P. Sullivan, W.J. Fisk, Parametric Evaluation of an Innovative Ultra-violet Photocatalytic Oxidation (UVPCO) Air Cleaning Technology for Indoor Applications, Lawrence Berkeley Natl. Lab., 2005, Accessed 11 June 2015 https://publications.lbl.gov/islandora/object/ir\%3A126144/.

[37] Y. Sun, L. Fang, D.P. Wyon, A. Wisthaler, L. Lagercrantz, P. Strøm-Tejsen, Experimental research on photocatalytic oxidation air purification technology applied to aircraft cabins, Build. Environ. 43 (2008) 258-268, http://dx.doi. org/10.1016/j.buildenv.2006.06.036.

[38] C. Young, T.M. Lim, K. Chiang, J. Scott, R. Amal, Photocatalytic oxidation of toluene and trichloroethylene in the gas-phase by metallised (Pt, Ag) titanium dioxide, Appl. Catal. B Environ. 78 (2008) 1-10, http://dx.doi.org/10.1016/j. apcatb.2007.08.011.

[39] M.E. Zorn, Photocatalytic oxidation of gas phase compounds in confined areas: investigation of multiple component systems, in: Proc. 13th Annu. Wis. Space Conf., Green Bay,WI, USA, 2003.

[40] F. Thevenet, O. Guaïtella, J.M. Herrmann, A. Rousseau, C. Guillard, Photocatalytic degradation of acetylene over various titanium dioxide-based photocatalysts, Appl. Catal. B Environ. 61 (2005) 58-68, http://dx.doi.org/10. 1016/j.apcatb.2005.03.015. 